\title{
Against the Grain
}

Volume 26 | Issue 1

Article 11

2014

\section{ATG Interviews Kari Paulson: Penthouse Interviews}

Tom Gilson

Against the Grain, gilsont@cofc.edu

Albert Joy

University of Vermont

Follow this and additional works at: https://docs.lib.purdue.edu/atg

Part of the Library and Information Science Commons

\section{Recommended Citation}

Gilson, Tom and Joy, Albert (2014) "ATG Interviews Kari Paulson: Penthouse Interviews," Against the Grain: Vol. $26:$ Iss. 1, Article 11. DOI: https://doi.org/10.7771/2380-176X.6654

This document has been made available through Purdue e-Pubs, a service of the Purdue University Libraries. Please contact epubs@purdue.edu for additional information. 


\section{VP, General Manager, eBooks at ProQuest}

\section{Charleston Conference, The Penthouse Interviews, Francis Marion Hotel}

by Tom Gilson (Associate Editor, Against the Grain) <gilsont@cofc.edu>

and Albert Joy (Acquisitions and Preservation Librarian, University of Vermont)

\begin{abstract}
ATG/Tom Gilson: Kari, your company, EBL, was acquired by ProQuest in January of 2013. How did the deal come about and what role did you play in the negotiation?

Kari Paulson: The deal really started as a conversation. For many years, Kevin Sayar, co-founder and President at ebrary, and I had been talking to each other about how we might collaborate, bring our services together in one way or another that would make sense for our customers, but there was never really the right opportunity to do so. In early 2011, ebrary was acquired by ProQuest LLC, and shortly after that Kevin assumed leadership of three additional ProQuest business units, Serials Solutions, Bowker, and RefWorks. Over the course of the last year, we just sort of started throwing some ideas around, and I think that those ideas grew to the point we felt that it would be the best thing for our customers and their patrons, the best thing for the service, the best thing for the companies, if we could join forces, bring our teams together, bring our services and products together and merge into a single entity.
\end{abstract}

ATG/TG: And what was your role in the negotiations?

KP: I was really involved from the perspective of "is this a good thing to do? If we do so, how would we do it?" And then I was heavily involved in all of the due diligence, in making sure that we were looking at all the right elements and that we were making all the right decisions.

ATG/Albert Joy: So, what did EBL bring that ebrary didn't? I mean, they each have slightly different policies; how are those going to meld together?

KP: EBL brings some different access models. The Non-Linear Lending model, for example, is one. Our particular implementation of demand-driven acquisition is slightly different as well; there are some different workflows that we bring. There is different content. There is a great deal of overlap, but there is specialty content in each of the platforms that don't overlap. EBL brings some of the back end services and enhanced workflow. I think, too, the team - EBL brings in a level of expertise that is quite compatible with ebrary's team. ebrary has a real expertise, especially around the subscription model that they've been doing so long, whereas EBL brings a great deal of expertise around demand-driven acquisition. By combining the teams, we really round out the strengths of the two.

ATG/AJ: So, do you see more multiple models then being offered by ProQuest? I have a parochial concern. We, at the Uni-

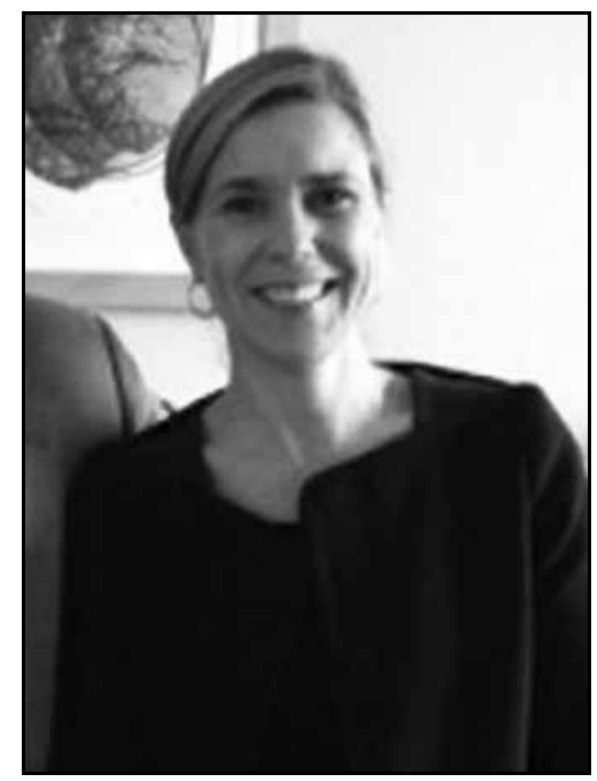

versity of Vermont, have used EBL in collaboration with $Y B P$, and with $Y B P$ we have had a very longstanding - originally it was an approval plan, and now it is a shelf-ready plan, and we very much like both the billing approach, that YBP bills us for the EBL materials, and they also de-duplicate so we don't have duplication. Do you see that continuing? Will ProQuest be able to maintain those policies?

KP: Absolutely. As we approach this, it isn't about choosing one model over the other or consolidating. It really is about choice. It's about offering the most choice, the most choice of content, the best choices in access models. And, you know, when you are selling a product that has limited choice - you have to say "these are the best things," because this is what you're selling. But when you have this wide choice of access models and content, then it becomes about consulting. It becomes about really understanding the needs of libraries, tailoring a solution, and utilizing the right options. So, what we hope to gain and what we are intending to gain out of this is to actually support more choices. Similarly, with the workflows that we have established with YBP, they are very important. We understand how important they are, and this isn't about becoming a self-contained unit within ProQuest. This is about integrating in all of the ways, in all of the places that you are, that libraries are, managing their acquisitions, managing their workflows, managing their collections. Yes, definitely - we will continue to support partnerships like the one we have with YBP.
ATG/AJ: You say that ebrary and EBL have some unique titles. Are there special subject areas or is it more different publishers for the two companies?

KP: It tends to be more around different publishers, and in some cases some publishers will prefer one access model over another. In some cases, it was just really a matter of where we had gotten to with our acquisition policies or acquisition programs, and some of it is accidental. It's not a perfect world.

ATG/TG: How do you - obviously, it sounds like you really don't feel like competitors anymore; how do you maintain the open communication that enables the two entities to merge and feel compatible and so on?

KP: Good question. I think it helps that right at the top, Kevin and I have had a very collegial relationship over the years; even though we were competitors, we tended to share our experiences and think about problems. I think we are equally concerned about the industry we're working in and the issues we're all facing. So, that was a good start, and when you get that cooperation at the top it helps set the stage, or set the environment, under which the rest of the team works together. There is a very good cultural fit between ebrary and EBL.

ATG/TG: Can you elaborate on that a little bit? That's interesting.

KP: Sure. We have come from similar backgrounds. We were both startups. We've been approaching similar challenges, but from slightly different points of view or slightly different places, but we've been working with eBooks more than ten years each. We've been growing organically along the way. There was, on both sides, a culture of innovation, a culture of creative problem solving, and sometimes cultures fit and sometimes they don't. This was pretty easy. It was actually easier than I had anticipated.

ATG/AJ: I think your policies have influenced one another as well over the years.

\section{KP: Absolutely.}

ATG/AJ: I'm curious now that you are under the ProQuest umbrella, this idea of a patron-driven model, I wonder if ProQuest is going to apply it beyond eBooks?

KP: Well, it's certainly something that we are looking at, and we hear from libraries that it's of interest, and we even, prior to ProQuest, on the EBL side, have always had that on the radar, that this could extend beyond the book content, so it is something that we are looking at and thinking about. No press releases yet [laughing].

continued on page 27 
Interview - Kari Paulson

from page 26

ATG/AJ: No. No. I was just wondering because ProQuest brings such an amount of content that you can apply these models beyond - it's funny because eBooks are really the newer things, but your models are very innovative and that could be applied to the older material as well. I look forward to seeing that happening. As an acquisitions librarian the "just-in-time" is very attractive and has always been attractive with eBooks and your policies.

KP: Right. One of the primary tasks at hand is interoperability between our products, interoperability between our content, making this content more usable side-by-side or the interplay between the content, and that is certainly something we're working on as a priority.

ATG/TG: We understand that the merger will take a total of 18 months. I mean, the full merger. Can you tell us what part of the process you're in right now?

ATG/AJ: And what the final company will look like in terms of structure and so on, and if you are planning a new name. Just fill us in on what's going on.

KP: Sure. We brought the teams together. We've integrated the sales teams and integrated the product teams. We have also integrated our management teams and the content teams. So, that aspect of bringing our people together we really are merged in that respect. We still have our individual platforms which we're continuing to develop and maintain. So, it's not the case of "now everything stops and we just work on this new combined platform." We are continuing to invest in the existing platforms, and we have staged out the development. Obviously we're going to bring the two platforms together onto one common platform. We'll be using a combination of both EBL and ebrary's tools and platforms as a framework for the future product. We will be launching a new version of LibCentral, which is the administrative and acquisition portal on EBL, and we're going to start the pilot phase at the end of this year. That will then become the framework for the new administration and acquisition portal for the combined product. With ebrary, we're launching a new reader in the middle of next year and that, combined with a redesigned user interface, will become the framework for user interface in the new combined product.

ATG/TG: The combined product - you have a date when that will actually be on the market?

KP: Our teams are "heads down" working on the combined product. We don't want to rush through this process and come out with a solution that isn't as good as it could be for our customers and their patrons, so we're aiming for mid- to late-2015.

ATG/TG: Can you give us the scoop on what the new name might be? [laughing]

KP: Nope. [laughing] We're taking our time - we're doing our research, making sure that whatever it is we decide resonates with our customers.
ATG/AJ: You'll be using beta sites to test the various aspects of the platform?

KP: Yes. Absolutely. And we've been on the road, holding customer forums across Australia, New Zealand, the UK, Europe, and here in the U.S. We've gathered together EBL customers, ebrary customers, and joint customers. We've spent lots of time talking through the plans and ideas, and hearing from customers what they like, what they don't like, what they want to make sure we continue to do and what they would like to see changed. We've been gathering all of this input and incorporating it as we make our plans. It's been great. You don't often have the time to do that with the kind of intensity that we have been able to through this process.

ATG/AJ: One of the interesting things at this year's Charleston Conference has been some talk about looking to the future for textbooks, especially in the digital world. I wonder if you are doing any thinking about different formats to replace academic textbooks and if you can talk at about that.

KP: Yes, textbooks are very much on our radar. It is something we hear about in every session and meeting — "what about textbooks?" It is an area we are investigating. We do have some plans for a pilot coming up for serving textbooks within the library in Australia in early 2014 . And these are with proper textbooks, not course adopted texts.

ATG/AJ: Right, that is the first part of the question. Is the traditional textbook replicating it in " $E$ " fashion?

KP: For the purpose of this experiment, yes. But, then we are also looking at delivery of textbooks to end-users as well. We are looking at the combination of both textbooks within the library setting, textbooks to end-users, and we don't have any exact plans that I can share with you now, except to say that it is something we are really circling around and figuring out what is our role here and what can we bring to this

ATG/AJ: I want to talk about affordability for college students, a very big topic, certainly around the country and certainly at my university, and any kind of work to make that easier, especially in the text material, and in thinking again of ProQuest and their large content collection, you would think there might be some possibilities for collaboration in that regard, to come up with new models for "supporting classes," let's call it.

KP: Certainly. And interaction with our research tools, what value we can bring to, not just getting the content, but the actual research.

ATG/AJ: Discoverability, the actual research process around utilizing these textbooks. That is very exciting.

ATG/TG: As Albert mentioned earlier, $E B L$ is kind of noted for being innovative, and we were wondering, now that the company is, in a sense, I don't know, is it doubling or tripling in size? It's going to be a much bigger company. What strategies are you guys going to have to ensure that that innovation remains alive in this new bigger company?

KP: I think that is a good question, and I don't know that we have a strategy necessarily, except that it is certainly a value. You know, it is a value I'm bringing to the group. It is something that is, for me, a priority and continuing to foster that kind of critical thinking. Innovation is everybody's job. We all have to contribute, and so I am trying to cultivate (and I think it already exists) a culture that lets that kind of critical thinking or creative problem-solving come out ahead, come out on top.

ATG/TG: I guess one of the other things I am interested in, what would you say or what do you say to folks who mention this is a bigger company, and you occupy a big part of the eBook space, what do you say to folks who are concerned that this is going to cut back on the competition and have negative price impacts for libraries?

KP: As we've consolidated and others have consolidated, new players have entered the market. We have JSTOR, we have Muse, we have an increasing number of publishers who have their own platforms. I don't think there's ever been more choice in terms of options for how you buy your eBooks and where you buy them. So, I think that will continue. I think in some ways, our getting bigger opens the door for smaller companies to come in.

ATG/TG: For another startup company to come in.

KP: To do something different, fulfill a niche model or content supply. Nobody can be everything to everyone, and we're not going to try to be everything to everyone, but we are going to try to offer the right choices to our customers. I totally understand the concern around competition, but it seems to me to be still a very healthy market, and I think it will continue to be; choices will continue to expand.

ATG/TG: As far as the eBook space goes, is there a place for things like self-publishing or open access and, even more broadly, what do you see the eBook space looking like in five years?

KP: These are a couple of the things that we are really considering and thinking about - what role we play in open access, what role we play in self-publishing and the technology. I think there will be, again, more choices or more ways that content is being made available, whether it is through stronger self-publishing channels, whether it is through increasing open access, I think these channels will evolve as they make sense. The technology is there to support it, so really the forum is there to test out these different things and if it's going to work, it'll stick.

ATG/AJ: It is interesting that we started in this industry with eBooks, but the technology you've developed is really applicable beyond that. I think of streaming media, which has only in the last few years become practical. Why shouldn't streaming media, for example, be part of the conversation? What I'm saying is that this is not necessarily all about eBooks, right? It's really the technology providing access to digital materials with different business models.

KP: So, yes, we are - the thing we do, or we aim to do, is to facilitate that ease of access, facilitate the workflow, make things continued on page 28 
Interview - Kari Paulson

from page 27

discoverable, make things easy to use, provide the research tools around it, whatever the content format is, so I think the next few years will be telling in terms of what happens with self-publishing, what happens with open access, what happens with some of these other ways of bringing content to the public.

ATG/TG: Speaking even more broadly, we talked about eBook space, in terms of library collections, where do you see things going in the next five or ten years? Obviously eBooks are going to be a big part of it, but what other developments do you see? Is there a place for print, for example, what do you think?

KP: Absolutely. Print will continue to have a place. There will continue to be, in some cases, a preference for print. I think print will work better for some content types more than others. When we talk about "E versus P," I don't think it's really a "versus," I think it's about "E and P," and just like different models serve different content better in "E," different formats serve different content better overall. We know libraries have challenges around space. We know they have challenges around budget. The print and the "E" really supplement each other. The "E" can make the print much more valuable by making it more discoverable or more "scannable," and the print will often provide a more immersive reading experience.

ATG/TG: One of the things that came up when we were talking to Stephen Bell earlier: we asked him how, because he presented this morning and talked about this notion of serendipity and just happening upon things, we asked him, and I wanted to ask you, how does that translate into the eBook space? How can people just "happen" upon eBooks like they do on the shelf in a library, just "Oh, I didn't even know it was there, and there it is!" How does that happen in the eBook space?

KP: We're seeing it happen now with eBooks in the demand-driven acquisition model. For example, I just came from a session, "Ebooks Down Under," and there were a couple of Australian universities that we work with who have been doing DDA for eight years now. The number of titles they can expose to their users with the "just-intime" delivery model behind it means that the students can pass their eyes over a greater number of resources. So, the serendipity of stumbling upon something that the library wouldn't have otherwise made available to them or discoverable to them and the ability to micro-transact means that the library can expose more things than they may not otherwise afford in their core collection or their collection building environment, than they can through these other mechanisms. So, that is one example of how that is happening.

ATG/AJ: So, as you expand your formats, do you see your platform as a supplement to or a complement to the current discovery engines? A lot of places have moved into these big discovery engines just to give that serendipity, but it almost sounds like, as you expand beyond simply eBooks, that might be what you're aiming towards with this innovative business model.

KP: Discovery and PDA or DDA are actually perfect for one another because it is a wider breadth of content and the ability to micro-transact or to make things available just at that second.

\section{ATG/AJ: I think it is very exciting.}

KP: It is exciting. In this session, there were some really fantastic stats, and both of these universities are spending 88 and $90 \%$ of their acquisition budgets electronically. We don't see that happening as frequently here in North America, but it is moving in that direction. The kinds of changes in behaviors and the different ways in which we are able to make this content available are exciting, and the stats are starting to flow from that now.

ATG/TG: So, you are seeing usage statistics that support this kind of purchasing model?

KP: Right. There was a statistic presented in this session about the books that were purchased in this way (through DDA). 98 or $99 \%$ of these books continued to have usage post purchase. We haven't seen these kinds of usage stats across preselected print content before.

ATG/AJ: Actually, research shows about $40 \%$ of the approval plans models never get use. Whereas with $\mathrm{PDA}$, we know there's one user already because that's the person who is requesting it. And statistics show that something that someone has requested has a much greater chance of being used again.

KP: Right. So, it's a combination. These books are more discoverable so they are being found more often, and what's being acquired is absolutely tied to what's needed. There are some interesting statistics coming out, and I think we still have so much to learn. The stats that came out of this presentation were absolutely encouraging and tell us that some of the things we're doing, we're doing right.
ATG/TG: I think what we normally end the interview with is what I kind of refer to as a trick question, but it's really not. If you were sitting in Albert's chair or sitting in my chair what question would you ask yourself?

KP: That's a tough one. What question would I ask myself? I might just set this up to make it really easy (laughing).

\section{ATG/AJ: What are your challenges?}

KP: I think we are in a challenging environment as we're shifting, print to "E"; when you hear of libraries spending $90 \%$ of their budget on electronic resources, that is a big shift, and there's a disruption associated with it. It wouldn't be so hard if we could just take this thing and flip it over and there was no change in behavior, but we see hiccups through this transition. The biggest challenge is to understand. When you're looking at short-term data and trying to understand what that means long-term, it is a challenge. It's something that we have to continue to pay attention to. We need to keep looking at what's happening in the immediate term, but we have to understand it in the context of the longer-term. We don't have that many years of experience with eBooks, but it's growing. Now, both ebrary and EBL have been around about 12 years. So, it's not an excuse to say we don't know. We have to really make sure we do know and that we are taking the time to understand, both within our world, but also within an industry as a whole. How is this impacting the libraries? How is this impacting publishers? We are a community, we have an ecosystem here, and we all play our part in maintaining a healthy environment.

ATG/TG: We all have a responsibility to gather the data and share it so that these kinds of decisions can be made in the most effective and efficient way for our users and for our budgets and for so on.

KP: Right. So that we're not looking at it just from within our silo, we really have to understand how our behavior and what we're saying with our data impacts the environment as a whole. And that is a challenge. We couldn't hire enough data analysts [laughing] to solve that completely. The challenge is prioritizing that and making sure we don't jump to conclusions.

ATG/TG: Kari, we really appreciate your taking the time to come over and talk to us. We've learned a lot, and it's been a lot of fun and, again, I want to thank you for doing this. It's been great.

KP: It's been my pleasure. Thank you.
Rumors

from page 25

and you will notice that Tony Horava (see above) wrote the report on SelfPub 2.0. Since self-publishing is currently not vetted, there is much resistance in colleges and universities to purchasing this type of material. There is an opportunity for libraries to vet this body of material which is doing nothing but growing!

Speaking of vetting self-published material, check out "Assuming the Risk for Your Own eBook" which gives a general overview of the publishing process and the peaks and valleys that are necessary to get something out there. The Data Conversion Laboratory, Inc.,(DCL) has many resources available on this topic. Did you meet the vivacious Laura Dawson of Bowker, and one of the coauthors of this white paper in Charleston?

http://www.dclab.com/resources/whitepapers-content-strategy

continued on page 47 